\title{
ОЦЕНКА ПОГРЕШНОСТИ ИЗМЕРЕНИЯ ПАРАМЕТРОВ ДВИЖЕНИЯ ПРОТЯЖЕННЫХ ОБЪЕКТОВ В УСЛОВИЯХ ИЗМЕНЯЮЩЕЙСЯ ДАЛЬНОСТИ*
}

\author{
АРТЮШЕНКО В. М. ${ }^{1}$, ВОЛОВАЧ В. И. ${ }^{2}$ \\ ${ }^{1}$ Финансово-технологическая академия, \\ Россия, Королев, 141070 МО, ул. Гагарина, 42 \\ ${ }^{2}$ Поволжский государственный университет сервиса, \\ Россия, Тольятти, 445677, ул. Гагарина, 4
}

\begin{abstract}
Аннотация. Рассмотрены вопросы, связанные с оценкой погрешности измерения параметров сигнала, содержащих информацию о движении лоцируемых протяженных объектов. Определены погрешности измерения информационных параметров полезного сигнала на фоне аддитивной негауссовской помехи в условиях изменяющейся дальности с учетом формы диаграммы направленности радиолокационного измерителя. Показано, что учет негауссовского характера аддитивной помехи, воздействующей на измеряемые информационные параметры обрабатываемого сигнала, позволяет значительно повысить потенциальную точность измерителя. Представлены результаты экспериментальных исследований радиолокационного измерителя, созданного с использованием полученных зависимостей, показывающие что точность такого измерителя, при прочих равных условиях, значительно выше, чем у аналогичных серийно выпускаемых образцов
\end{abstract}

Ключевые слова: радиолокационный измеритель; протяженный объект; диаграмма направленности; отношение сигнал/помеха; погрешность измерения

\section{ВВЕДЕНИЕ}

В радиолокации вопросы измерения (оценки) параметров сигнала, несущих информацию о движении лоцируемых объектов (целей), являются традиционными и подробно рассмотрены [1-3]. При этом хорошо изучены вопросы радиолокационного измерения точечных [4-6] и отчасти дискретных [7, 8] целей. Вместе с тем, многие аспекты, связанные с измерением параметров сигнала в системах ближней радиолокации, содержащих инфор- мацию о движении объектов, находящихся на относительно небольших расстояниях от радиолокационных измерителей (РИ), представляющих собой разновидность радиотехнических устройств ближнего действия, являются недостаточно изученными и имеют ряд специфических особенностей как теоретического, так и практического характера [9-11].

Специфической особенностью работы РИ в условиях небольших удалений лоцируемых объектов является то, что характеристики об-

* Работа выполнена в рамках фундаментальной НИР, финансируемой из средств Минобрнауки РФ

(Государственное задание на 2014 г., код 226). 